\title{
Downregulation of Cortical Inhibition Mediates Ocular Dominance Plasticity during the Critical Period
}

\author{
Wen-pei Ma, ${ }^{1 \star}$ Ya-tang $\mathrm{Li}^{1,3 \star}$ and Huizhong Whit Tao ${ }^{1,2}$ \\ ${ }^{1}$ Zilkha Neurogenetic Institute, ${ }^{2}$ Department of Cell and Neurobiology, ${ }^{3}$ Graduate Program in Physiology and Biophysics, Keck School of Medicine, \\ University of Southern California, Los Angeles, California 90033
}

\begin{abstract}
Monocular deprivation (MD) during the critical period (CP) shifts ocular dominance (OD) of cortical responsiveness toward the nondeprived eye. The synaptic mechanisms underlying MD-induced OD plasticity, in particular the contribution of cortical inhibition to the plasticity, have remained unsolved. In this study, using in vivo whole-cell voltage-clamp recordings, we revealed eye-specific excitatory and inhibitory synaptic inputs to layer 4 excitatory neurons in mouse primary visual cortex (V1) at a developmental stage close to the end of CP. We found in normally reared mice that ocular preference is primarily determined by the contralateral bias of excitatory input and that inhibition does not play an active role in shaping OD. MD results in a parallel reduction of excitation and inhibition driven by the deprived eye, while reducing the inhibition but preserving the excitation driven by the nondeprived eye. MD of longer periods causes larger changes in synaptic amplitude than MD of shorter periods. Furthermore, MD resulted in a shortening of onset latencies of synaptic inputs activated by both contralateral and ipsilateral eye stimulation, while the relative temporal relationship between excitation and inhibition driven by the same eye was not significantly affected. Our results suggest that OD plasticity is largely attributed to a reduction of feedforward input representing the deprived eye, and that an unexpected weakening of cortical inhibitory connections accounts for the increased responsiveness to the nondeprived eye.
\end{abstract}

\section{Introduction}

Monocular deprivation (MD)-induced ocular dominance plasticity during the critical period (CP) has been a classical model for studying the experience-dependent development of visual cortical circuits. MD reduces cortical responsiveness to the deprived eye, while it slowly increases responsiveness to the open eye (Tsumoto and Suda, 1978; Mitzdorf and Singer, 1980; Frenkel and Bear, 2004; Mrsic-Flogel et al., 2007; Kaneko et al., 2008; Medini, 2011). Since cortical responsiveness is primarily determined by the interplay of visually evoked, eye-specific excitatory and inhibitory synaptic inputs to individual cortical neurons, revealing MD-induced changes of synaptic inputs is key to understanding how cortical circuits are modified by experience. Previous studies on ocular dominance (OD) plasticity have mostly relied on direct or indirect measurements of neuronal output response (spike, optic signal, and $\mathrm{Ca}^{2+}$ responses) or of extracellular ensemble response [visually evoked potential (VEP); Smith and Bear, 2010]. Due to the technical limitations of these approaches, MDinduced changes of visually driven synaptic inputs could not be easily derived from those previous results. In principle, two types

\footnotetext{
Received Dec. 6, 2012; revised April 11, 2013; accepted May 31, 2013.

Author contributions: H.W.T. designed research; W.-p.M. and Y.-t.L. performed research; W.-p.M., Y.-t.L., and H.W.T. analyzed data; H.W.T. wrote the paper.

This work was supported by grants to H.W.T. from the National Institutes of Health (EY019049 and EY022478) and the Kirchgessner Foundation. We thank Dr. Aaron Magee, for technical help, and Dr. Li I. Zhang, for helpful discussions.

${ }^{*}$ W.-p.M and Y.-t.L. contributed equally to this work.

Correspondence should be addressed to H.W. Tao at the above address. E-mail: htao@usc.edu.

DOI:10.1523/JNEUROSCI.5598-12.2013

Copyright $\odot 2013$ the authors $\quad 0270-6474 / 13 / 3311276-05 \$ 15.00 / 0$
}

of synaptic modification may account for the MD-induced reduction of cortical responsiveness to the deprived eye. First, excitatory drive into the cortex (i.e., thalamocortical input) from the deprived eye could be weakened, thereby decreasing the response evoked by the deprived eye (Frenkel and Bear, 2004). Second, as suggested by the ex vivo result in the monocular visual cortex that MD induces a potentiation of feedback inhibition from fast-spiking cells (Maffei et al., 2006), cortical inhibition driven by the deprived eye could be enhanced following MD, thereby suppressing the response evoked by that eye. Similarly, both an excitatory and inhibitory mechanism can mediate the increased responsiveness to the open eye.

Although a large body of work supports an excitatory mechanism (e.g., Heynen et al., 2003; Crozier et al., 2007; Yoon et al., 2009; Khibnik et al., 2010), potential inhibitory mechanisms have been less clearly addressed (Smith and Bear, 2010). The inhibitory input to excitatory neurons derives from a variety of presynaptic inhibitory neurons (Markram et al., 2004), which may exhibit differential responses to MD. Noticeably, previous studies using different approaches have generated different results on inhibitory neuron plasticity, from no change even after longterm MD (Mainardi et al., 2009), to shifting OD in favor of the open eye (Gandhi et al., 2008; Kameyama et al., 2010), and to shifting OD bidirectionally depending on the duration of MD (Yazaki-Sugiyama et al., 2009). As such, the role of inhibitory input changes in the expression of OD plasticity is not easily understood based on those previous results. Here, we addressed this issue by directly examining visually evoked eye-specific synaptic conductances in cortical neurons in vivo during normal development and after MD. Our results generated insights 
into MD-induced plasticity of both excitatory and inhibitory circuits.

\section{Materials and Methods}

Animal preparation and cortical mapping. Experimental procedures were approved by the Animal Care and Use Committee of the University of Southern California. Female wild-type C57BL/6 mice were sedated with chlorprothixene $(10 \mathrm{mg} / \mathrm{kg})$ and anesthetized with urethane $(1.2 \mathrm{~g} / \mathrm{kg})$. Surgery to expose the primary visual cortex (V1) was performed as previously described (Niell and Stryker, 2008; Liu et al., 2010, 2011; Li et al., 2012). The eye movement and the receptive field (RF) drift of single units were negligible within the time windows of recordings (Mangini and Pearlman, 1980; Liu et al., 2010). V1 was mapped by recording multiunit spikes to flash sparse stimuli. Based on RF centers of 5-6 cortical sites, the retinotopic map was determined and the binocular and monocular areas were identified. Later recordings were performed in the binocular zone, with RF centers located at $\sim 0-10^{\circ}$ azimuth.

Monocular deprivation. Monocular eyelid suture was performed during brief anesthesia with $70 \mathrm{mg} / \mathrm{kg}$ ketamine, $3.5 \mathrm{mg} / \mathrm{kg}$ xylazine hydrochloride, and $0.7 \mathrm{mg} / \mathrm{kg}$ acepromazine maleate, intraperitoneally (Maffei et al., 2006). The eyelid was covered with a thin layer of xylocaine gel, and the lid was secured with three mattress sutures (6-0 Vicryl). At the end of the deprivation period, mice were anesthetized, stitches were removed, and lid margins were separated. Eyes were flushed with sterile saline and checked for clarity under a microscope. Only mice without corneal opacities or signs of infection were used. MD was performed in three ways: (1) for a period of 2-3 d, deprivation was initiated at postnatal (P) day 28; (2) for a period of $5-6 \mathrm{~d}$, deprivation was initiated at P26; (3) for a period of $10-14 \mathrm{~d}$, deprivation was initiated at P18-P21. In all cases, mice were examined at $\mathrm{P} 30-\mathrm{P} 33$.

In vivo electrophysiology. Whole-cell recordings were performed with an Axopatch 200B (Molecular Devices) as previously described (Liu et al., 2010, 2011; Li et al., 2012). The patch pipette had a tip opening of $\sim 2$ $\mu \mathrm{m}(4-5 \mathrm{M} \Omega)$. The $\mathrm{Cs}^{+}$-based intrapipette solution contained the following (in mM): 125 Cs-gluconate, 5 TEA-Cl, 4 MgATP, 0.3 GTP, 8 phosphocreatine, 10 HEPES, 10 EGTA, 2 CsCl, 1 QX-314, 0.75 MK-801, $1 \%$ biocytin, $\mathrm{pH} 7.25$. The pipette capacitance and whole-cell capacitance were compensated completely, and the series resistance was compensated by $50-60 \%$ (at $100 \mu \mathrm{s} \mathrm{lag}$ ) to achieve an effective value of $10-15$ $\mathrm{M} \Omega$. An $11 \mathrm{mV}$ junction potential was corrected. Signals were filtered at $2 \mathrm{kHz}$ and sampled at $10 \mathrm{kHz}$. The evoked excitatory and inhibitory currents were recorded while clamping the cell at -70 and $0 \mathrm{mV}$, respectively. All neurons recorded in this study were located at a depth of 375-500 $\mu \mathrm{m}$ below the pia according to the microdrive reading, corresponding to layer 4 . The morphology was reconstructed successfully for 11 cells following the standard protocol for biocytin staining (Liu et al., 2010), confirming that the recorded cells were layer 4 pyramidal cells (one example is shown in Fig. 1B). Therefore, similar as previously reported (Liu et al., 2010), our recordings with relatively large pipettes highly biased sampling toward excitatory neurons. VEP and extracellular spikes were recorded in layer 4 using a patch pipette filled with artificial CSF. Signals were filtered at $10 \mathrm{kHz}$ and sampled at $20 \mathrm{kHz}$. Single units were sorted off-line by custom-made LabVIEW software according to spike amplitude and shape.

Visual stimulation. Stimuli were created using Matlab with Psychophysics Toolbox and displayed with a gamma-corrected LCD monitor (refresh rate, $75 \mathrm{~Hz}$; maximum luminance, $280 \mathrm{~cd} / \mathrm{m}^{2}$ ) placed $0.25 \mathrm{~m}$ away from the mouse. The center of the monitor was placed at $0^{\circ}$ azimuth, $0^{\circ}$ elevation, and it covered $\pm 35^{\circ}$ horizontally and $\pm 27^{\circ}$ vertically of the visual field. One eye was covered by a custom-made shutter that could slide between contralateral and ipsilateral eyes (Fig. 1A). Two types of stimulation were applied: (1) drifting sinusoidal gratings $(2 \mathrm{~Hz} ; 0.04$ cycle $/{ }^{\circ} ; 3$ cycles; contrast, $95 \%$ ) at the preferred orientation; (2) flash noise (duration, $200 \mathrm{~ms}$; contrast, 95\%). For each synaptic response, the grating stimulus was repeated 10 times, or 20-30 randomly generated noise patterns were applied. Interstimulus interval was $8 \mathrm{~s}$.

Data analysis. Responses were averaged by trials. Synaptic currents to gratings were further averaged by cycles and smoothed by averaging through a $40 \mathrm{~ms}$ sliding window (Li et al., 2012). Excitatory and inhibi- tory synaptic conductances were derived according to the following equation (Li et al., 2012): $\Delta I(t)=G_{e}(t)\left[V(t)-E_{e}\right]+G_{i}(t)\left[V(t)-E_{i}\right]$.

$\Delta I(t)$ is the amplitude of synaptic current relative to the resting current; $G_{e}$ and $G_{i}$ are the excitatory and inhibitory synaptic conductance respectively; $V(t)$ is the membrane voltage; and $E_{e}(0 \mathrm{mV})$ and $E_{i}(-70$ $\mathrm{mV})$ are the reversal potentials. The values of $E_{e}$ and $E_{i}$ were set by the ionic composition of the pipette solution and the CSF (Segal, 1993; Tan et al., 2004). $V(t)$ is corrected by $V(t)=V_{\mathrm{h}}-R_{s}{ }^{*} I(t)$, where $R_{s}$ is the effective series resistance and $V_{\mathrm{h}}$ is the applied holding voltage. Measurement of currents at two different voltages yielded a system of two equations that could be solved for $G_{e}$ and $G_{i}$ at any particular $t$. We used the bootstrapping method ( $\mathrm{Li}$ et al., 2012) to evaluate the variability of the derived conductance. For flash stimulation, peak synaptic conductance and VEP response were identified within a $300 \mathrm{~ms}$ window after the onset of the response. Conductance values within a $40 \mathrm{~ms}$ window around the maximum conductance were averaged to represent the response level. For grating stimulation, peak conductance of cycle-averaged response was measured. An ocular dominance index (ODI) was calculated as $\left(R_{\text {contra }}-R_{\mathrm{ipsi}}\right) /\left(R_{\text {contra }}+R_{\mathrm{ipsi}}\right)$. Excitation/inhibition (E/I) ratio was calculated based on peak conductances.

The onset of evoked synaptic responses was determined through the following steps. First, the evoked responses were visually identified based on their reliability among trials, and potential spontaneous currents (frequency of which was relatively low) were excluded. Second, the response onset was determined at the time point where the evoked response amplitude was 3 SDs greater than currents during blank periods. We also visually examined the response traces to verify each identified onset timing. The onset latencies were then averaged for each cell.

\section{Results}

\section{Same ocular dominance of excitation and inhibition in control mice}

We first examined how the ocular preference of cortical neurons was shaped by excitatory and inhibitory synaptic inputs. In vivo whole-cell voltage-clamp recordings were made from excitatory neurons in layer 4 (see Materials and Methods), the major thalamorecipient layer, in the binocular area of V1 of normally reared mice (Fig. 1A), at a stage close to the end of the CP (P30$\mathrm{P} 33$ ). The linearity of the current-voltage relationship and the proximity of the observed reversal potential of the earliest evoked synaptic currents to the theoretical reversal potential of excitatory currents (i.e., $0 \mathrm{mV}$ ) suggest that the recorded cells were clamped reasonably well (Fig. 1B). Excitatory and inhibitory currents were dissected by clamping the cell's membrane potential at -70 and $0 \mathrm{mV}$ respectively (Fig. $1 C, D$ ). Synaptic conductances were derived from the recorded currents (Fig. $1 C, D$; see Materials and Methods). We found that excitation evoked by contralateraleye stimulation was in general stronger than ipsilateral-eye stimulation, and this is the case for responses to both flash noise stimuli and moving sinusoidal gratings. Similar as excitation, inhibition also exhibited a contralateral bias (Fig. 1C,D). From peak conductances, we calculated an ODI. As shown in Figure 1E, ODI of inhibition was positively correlated with that of excitation. In the great majority of cells, both excitation and inhibition exhibited an ODI $>0$, indicating a contralateral bias. On average, the E/I ratio was not different between contralateral and ipsilateral stimulation (Fig. $1 F$ ). Accordingly, ODI of excitation, which had a net positive value, was similar as that of inhibition, and this is the case for both flash-noise and moving-grating responses (Fig. $1 G)$. In addition, ODIs of both excitation and inhibition were similar as that of VEP response (Fig. 1G). These results demonstrate that the excitation-inhibition balance is the same for contralateral and ipsilateral eyes. The contralateral dominance of cortical responses is already determined by the contralateral bias of excitatory input. Inhibition does not play an active role in 
A

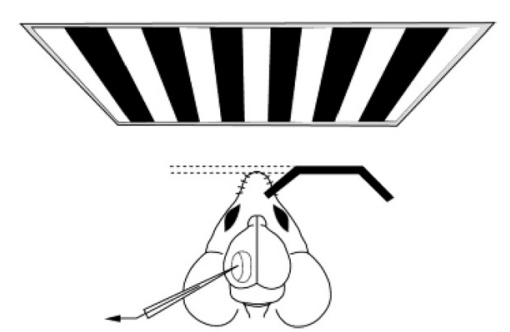

C

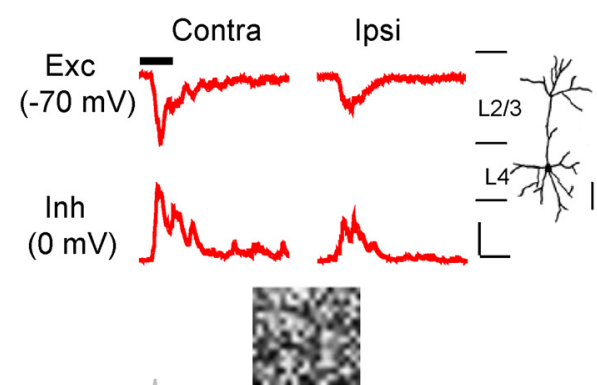

$\mathrm{D}$

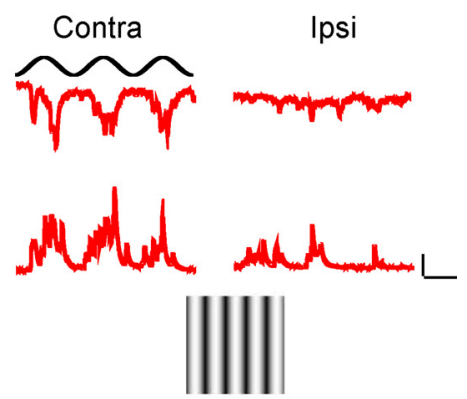

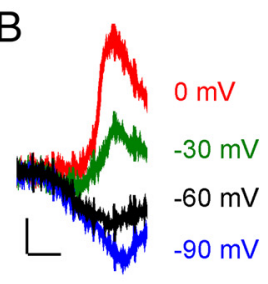

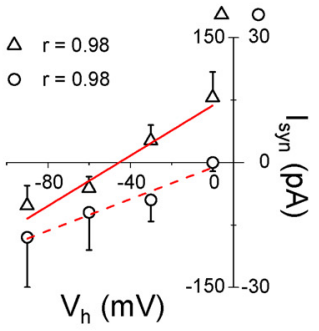

$\mathrm{Ge}$

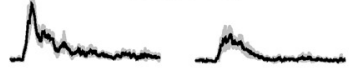

$\mathrm{Gi}$

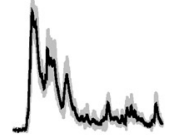

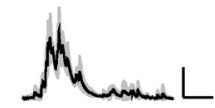

Ge

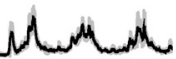

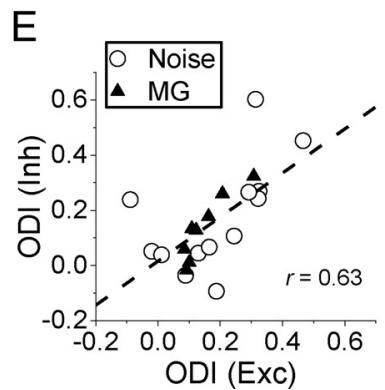
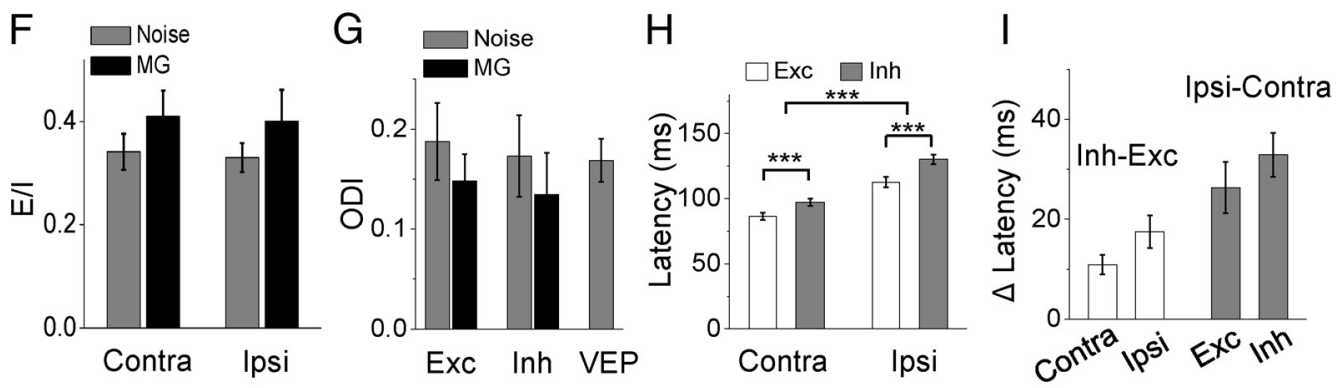

Figure 1. Both excitation and inhibition have a contralateral bias in normally reared mice. $\boldsymbol{A}$, Schematic drawing of the experimental setup. The computer monitor was placed in front of the mouse. One of two eyes was blocked alternately by a sliding eye shutter. Recording was made in the binocular area of V1. B, Left, Synaptic currents evoked by a flash stimulus recorded under different membrane potentials in a neuron. Scale bars: $20 \mathrm{pA}, 20 \mathrm{~ms}$. Right, Mean \pm SD of currents within a $5 \mathrm{~ms}$ time window after the earliest response onset (circle) and around the response peak (triangle), plotted as a function of membrane voltage. Best-fit linear regression lines are shown. The intercept of $x$-axis indicates the reversal potential. C, Top, Average excitatory and inhibitory currents evoked by contralateral and ipsilateral stimulation in an example cell. Scale bars: excitation (Exc), $0.1 \mathrm{nA}$; inhibition (Inh), $0.21 \mathrm{nA} ; 200 \mathrm{~ms}$. A sample noise pattern for flash stimulation is shown. Right inset, The reconstructed morphology of the cell showing that it was a pyramidal neuron located in layer 4 (L4). Scale bar, $50 \mu \mathrm{m}$. Bottom, Synaptic conductances derived from the currents. Shading indicates $95 \%$ confidence level. Scale bars: $2 \mathrm{nA}, 200 \mathrm{~ms}$. D, Synaptic responses to moving sinusoidal gratings in another cell. The three stimulus cycles were marked on top. Scale bars: Exc, $0.1 \mathrm{nA}$; Inh, $0.14 \mathrm{nA} ; 2 \mathrm{nS} ; 300 \mathrm{~ms}$. E, ODI of inhibition versus that of excitation plotted for individual cells. Dash line is the best-fit linear regression line. $N=13$ cells (from 13 mice) for noise stimulation and 9 cells (9 mice) for moving grating (MG) stimulation. $F$, E/I ratio for contralateral and ipsilateral responses. Error bar, SE. G, ODI of excitation, inhibition, as well as VEP response. There is no significant difference between Exc and $\operatorname{lnh}(p>0.5$, paired $t$ test). Error bar, SE. $N=22$ for VEP. $\boldsymbol{H}$, Onset latencies of excitatory (white) and inhibitory (gray) responses to flash noise stimuli. Error bar, SE. $N=$ 13. ${ }^{* *} p<0.001$, paired $t$ test between excitation and inhibition, and between contralateral and ipsilateral responses. I, Onset latency difference between excitation and inhibition (white), or between contralateral and ipsilateral responses (gray).

shaping ocular preference, as under a constant $\mathrm{E} / \mathrm{I}$ ratio the output response will increase with the increase of excitation (Liu et al., 2011). Our results are reminiscent of several previous studies showing that inhibitory neurons, like excitatory neurons, exhibit a strong contralateral bias (Gandhi et al., 2008; Mainardi et al., 2009; Kameyama et al., 2010; but see Yazaki-Sugiyama et al., 2009).

From the responses to flash stimuli, we also analyzed their onset latencies. In general, the contralateral response exhibited a significantly shorter delay than the ipsilateral response (Fig. $1 H$ ). For both excitation and inhibition, the contralateral response preceded the ipsilateral response by $\sim 30 \mathrm{~ms}$ (Fig. 1I, gray). Such delay difference was also observed for the VEP response (data not shown). This difference may be due at least partially to differential conduction speeds of afferent axons representing different eyes. For both contralateral and ipsilateral stimulation, inhibition followed excitation after a delay (Fig. 1I, white), which is consistent with the notion that inhibition is polysynaptic in nature (i.e., cortically driven), whereas the onset of excitation is determined by direct thalamocortical input.
MD-induced ocular dominance shifts of cortical responsiveness

Before examining MD-induced synaptic changes, we first verified that MD shifted OD of cortical responses. Three different MD durations, 2-3 d (MD3D), 5-6 d (MD6D), and $\sim 2$ weeks (MD2W), were applied (see Materials and Methods) to examine whether the level and polarity of potential synaptic changes were dependent on MD duration. All treatments covered the peak of CP (P28; Hensch, 2005). We recorded in layer 4 the VEP and single-unit spike responses to flash noise stimuli at P30-P33. As shown in Figure 2A (gray), MD3D resulted in a dramatic decrease in ODI of both VEP and spike responses, which could be attributed mainly to a weakening of the deprived-eye (contralateral) response (Fig. 2B,C). For longer periods of MD, we observed a larger and larger shift of ODI toward negative values (Fig. $2 \mathrm{~A}$, black and red), indicating an increasing ipsilateral dominance. This change of ODI was due to an enhancement of the nondeprived-eye (ipsilateral) response, which was accompanied by a slight recovery of the contralateral response (Fig. $2 B, C$ ). MD2W resulted in a significantly larger increase of ipsilateral 

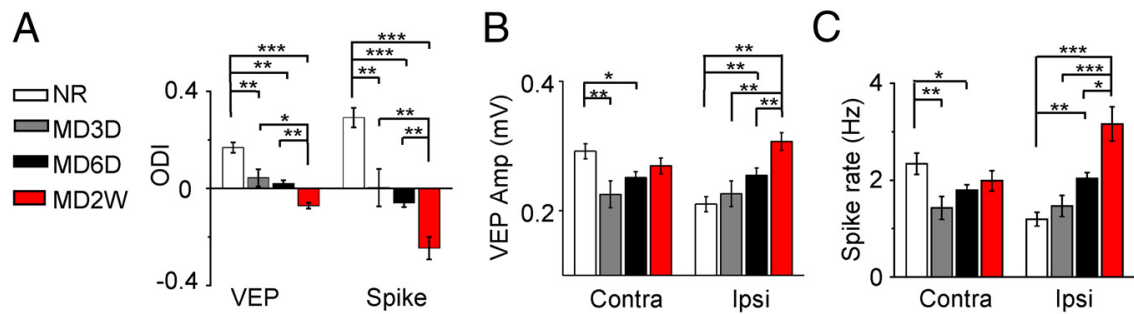

D

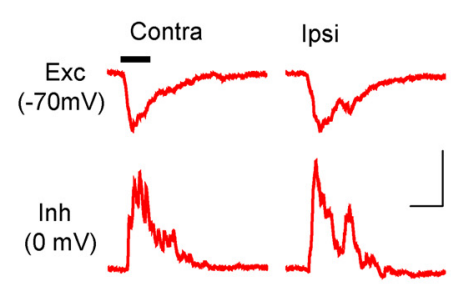

E

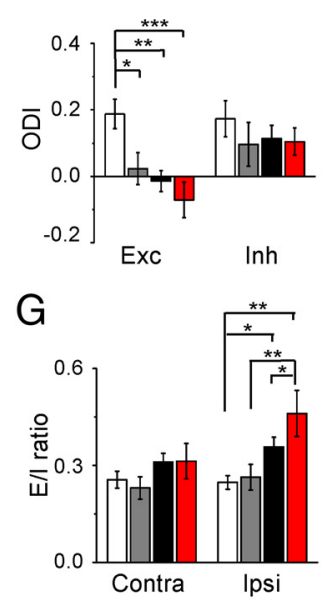

$\mathrm{F}$
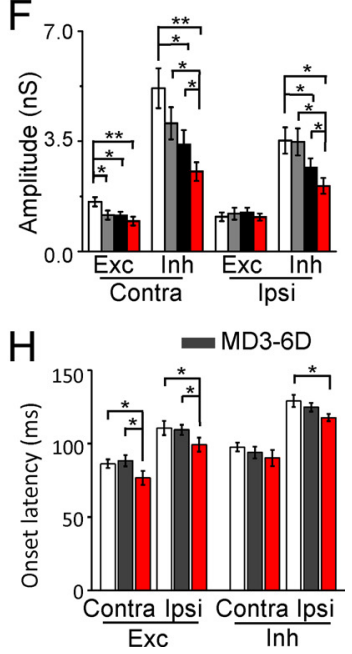

Figure 2. MD induced decreases of inhibition for both deprived and nondeprived eyes. $A, 0 D I$ of VEP and spike responses in normally reared mice (NR, $n=22)$ and mice following $\operatorname{MD3D}(n=13), \operatorname{MD6D}(n=28)$, and $\operatorname{MD} 2 \mathrm{~W}(n=22)$. Error bar, SE. ${ }^{*} p<$ $0.05,{ }^{* *} p<0.01,{ }^{* * *} p<0.001$, one-way ANOVA and post hoc test (same for the rest of figures). $\boldsymbol{B}$, Average VEP amplitudes in four groups of mice. $\boldsymbol{C}$, Average spike rates. $\boldsymbol{D}$, Top, Average excitatory and inhibitory currents to flash noise stimuli in an example cell after MD6D. Bottom, Synaptic conductances derived from the currents. Scale bars: top, $0.1 \mathrm{nA}$; bottom, $1 \mathrm{nS} ; 200 \mathrm{~ms}$. $\boldsymbol{E}, 0 \mathrm{DI}$ of excitation and inhibition in control mice (white, $n=13$ ) and mice following MD3D (gray, $n=11$ cells from 11 mice), MD6D (black, $n=15$ cells, 14 mice) and MD2W (red, $n=15$ cells, 15 mice). $F$, Average peak excitatory and inhibitory conductances evoked by flash noise stimuli. $\mathbf{G}$, E/I ratio for contralateral and ipsilateral stimulation. $\boldsymbol{H}, 0$ nset latencies of excitatory and inhibitory responses driven contralaterally and ipsilaterally. Gray columns represent combined data of MD3D and MD6D.

response than MD6D (Fig. $2 \mathrm{~B}, \mathrm{C}$ ). The shift of ODI was larger for spike than VEP response. These results are consistent with previous reports (Frenkel and Bear, 2004; Mrsic-Flogel et al., 2007; Kaneko et al., 2008; Yazaki-Sugiyama et al., 2009; Medini, 2011), in particular by showing that a delayed enhancement of ipsilateral response contributes to OD plasticity.

\section{MD-induced reduction of contralateral and ipsilateral inhibition}

We performed voltage-clamp recordings in animals with MD experiences (Fig. 2D). MD of either short or long durations resulted in a significant decrease of ODI of excitation (Fig. 2E). On the other hand, MD did not significantly affect ODI of inhibition (Fig. 2E). We compared the absolute levels of synaptic responses between experimental conditions (Fig. $2 F$ ). For the deprived (contralateral) eye, MD induced a significant reduction of excitatory input strength. Inhibition was reduced in parallel, so that the E/I ratio was relatively unaltered (Fig. $2 G$ ). In contrast, for the nondeprived (ipsilateral) eye, excitation was not changed while inhibition was significantly reduced by MD6D and MD2W, but not MD3D (Fig. 2F). This leads to a significantly increased E/I ratio following MD6D and MD2W (Fig. 2G). MD2W resulted in a larger decrease of inhibition than MD of shorter periods (Fig. $2 F$ ). The concurrent reduction of contralateral and ipsilateral inhibition explains why ODI of inhibition was not significantly altered (Fig. 2E). Consistent with flash noise responses, the synaptic responses to moving gratings also exhibited a significant increase in $\mathrm{E} / \mathrm{I}$ ratio for the nondeprived eye but not the deprived eye following MD of 6-12 d [contralateral stimulation: $0.41 \pm 0.05$ (SE) for control and $0.46 \pm$ 0.06 after $\mathrm{MD}, p>0.05$; ipsilateral stimulation: $0.40 \pm 0.06$ for control and $0.53 \pm$ 0.04 after $\mathrm{MD}, p<0.01 ; n=9$ control cells and 8 cells from $8 \mathrm{MD}$ mice, $t$ test].

\section{MD-induced changes in response delays}

For the responses to flash stimuli, we also examined their temporal delays. Interestingly, MD2W but not MD of shorter durations resulted in a significant shortening of onset latencies of all eye-specific synaptic responses except the contralateral inhibition (Fig. 2H). The mechanism underlying this shortening of response delay is currently unknown. One possibility could be an MD-induced change of conduction speed of retinal or LGN afferents in an eye-unspecific manner. As for the contralateral inhibition, the shortened delay of afferent input in inhibitory neurons may be largely compensated by a prolonged integration time for spike generation (due to reduced excitation), so that the net delay of inhibition to excitatory neurons is not significantly altered (Fig. $2 H$ ). Importantly, the delay difference between contralaterally and ipsilaterally evoked excitation, or between excitation and inhibition representing the same eye, was not significantly changed following $\mathrm{MD}(p>0.05, t$ test $)$, suggesting that the potential changes in conduction speed would not significantly affect the relative temporal relationship between excitatory and inhibitory inputs to a cortical neuron.

\section{Discussion}

Consistent with previous results (Khibnik et al., 2010), our study indicates that the MD-induced reduction of deprived-eye responsiveness is mainly attributed to reduced excitatory drive. Cortical inhibition, by decreasing concurrently with excitation, does not play an active role in suppressing the deprived-eye response. The reduction of the deprived-eye inhibition observed after MD of different durations challenges conclusions from a previous study (Yazaki-Sugiyama et al., 2009) that predicted enhanced deprived-eye inhibition after short-term MD due to an anti-Hebbian plasticity of fast-spiking neurons. However, the reduction of deprived-eye inhibition observed here is in agreement with some other studies showing that MD shifts OD of inhibitory neurons in the same direction as excitatory neurons (Gandhi et al., 2008; Kameyama et al., 2010). It is worth noting that results on plasticity of inhibitory neurons remain controversial. Because input from different types of inhibitory neurons likely contributed to the recorded inhibition, a more systematic study of MD-induced plasticity of inhibitory cell types is necessary to resolve the discrepancy.

The observed synaptic changes can be explained by several possibilities. While the reduced excitation could be largely attributed to a reduction of thalamocortical drive, the reduced inhibi- 
tion may result from the reduced excitatory drive to inhibitory neurons, the weakened inhibitory connections to pyramidal neurons, or a combination of both. Since there is no known plasticity mechanism that would lead to reduced excitatory drive from the nondeprived eye, we postulate that a weakening of inhibitory connections may be the main mechanism underlying the reduced nondeprived-eye inhibition. Such weakening of inhibitory connections may be a homeostatic regulation in response to a general reduction of activity level (Hartman et al., 2006), and is also reminiscent of results in adult cortex that MD for a few days increases loss of inhibitory synapses (Chen et al., 2012; van Versendaal et al., 2012). Since inhibitory neurons respond to both contralateral and ipsilateral eye stimulation (Gandhi et al., 2008; Yazaki-Sugiyama et al., 2009; Kameyama et al., 2010), the weakening of inhibitory synapses would generate a noneyespecific effect. Indeed, for the deprived eye, inhibition tended to decrease more than excitation (Fig. $2 F$ ), consistent with inhibitory synapses being weakened in addition to reduced excitatory drive. Future recordings of synaptic inputs to inhibitory neurons are needed to probe further into the synaptic mechanisms for $\mathrm{OD}$ plasticity.

Together, our study demonstrates that the increased open-eye responsiveness, commonly viewed as a result of homeostatic upregulation of excitatory synapses (Mrsic-Flogel et al., 2007; Kaneko et al., 2008; Maffei and Turrigiano, 2008), can be attributed instead to a downregulation of inhibition. Our data have revealed an unexpected role of inhibitory circuit modifications in the expression of CP-dependent OD plasticity.

\section{References}

Chen JL, Villa KL, Cha JW, So PT, Kubota Y, Nedivi E (2012) Clustered dynamics of inhibitory synapses and dendritic spines in the adult neocortex. Neuron 74:361-373. CrossRef Medline

Crozier RA, Wang Y, Liu CH, Bear MF (2007) Deprivation-induced synaptic depression by distinct mechanisms in different layers of mouse visual cortex. Proc Natl Acad Sci U S A 104:1383-1388. CrossRef Medline

Frenkel MY, Bear MF (2004) How monocular deprivation shifts ocular dominance in visual cortex of young mice. Neuron 44:917-923. CrossRef Medline

Gandhi SP, Yanagawa Y, Stryker MP (2008) Delayed plasticity of inhibitory neurons in developing visual cortex. Proc Natl Acad Sci U S A 105:16797-16802. CrossRef Medline

Hartman KN, Pal SK, Burrone J, Murthy VN (2006) Activity-dependent regulation of inhibitory synaptic transmission in hippocampal neurons. Nat Neurosci 9:642-649. CrossRef Medline

Hensch TK (2005) Critical period plasticity in local cortical circuits. Nat Rev Neurosci 6:877-888. CrossRef Medline

Heynen AJ, Yoon BJ, Liu CH, Chung HJ, Huganir RL, Bear MF (2003) Molecular mechanism for loss of visual cortical responsiveness following brief monocular deprivation. Nat Neurosci 6:854-862. CrossRef Medline

Kameyama K, Sohya K, Ebina T, Fukuda A, Yanagawa Y, Tsumoto T (2010) Difference in binocularity and ocular dominance plasticity between GABAergic and excitatory cortical neurons. J Neurosci 30:1551-1559. CrossRef Medline

Kaneko M, Stellwagen D, Malenka RC, Stryker MP (2008) Tumor necrosis factor-alpha mediates one component of competitive, experience- dependent plasticity in developing visual cortex. Neuron 58:673-680. CrossRef Medline

Khibnik LA, Cho KK, Bear MF (2010) Relative contribution of feedforward excitatory connections to expression of ocular dominance plasticity in layer 4 of visual cortex. Neuron 66:493-500. CrossRef Medline

Li YT, Ma WP, Pan CJ, Zhang LI, Tao HW (2012) Broadening of cortical inhibition mediates developmental sharpening of orientation selectivity. J Neurosci 32:3981-3991. CrossRef Medline

Liu BH, Li P, Sun YJ, Li YT, Zhang LI, Tao HW (2010) Intervening inhibition underlies simple-cell receptive field structure in visual cortex. Nat Neurosci 13:89-96. CrossRef Medline

Liu BH, Li YT, Ma WP, Pan CJ, Zhang LI, Tao HW (2011) Broad inhibition sharpens orientation selectivity by expanding input dynamic range in mouse simple cells. Neuron 71:542-554. CrossRef Medline

Maffei A, Turrigiano GG (2008) Multiple modes of network homeostasis in visual cortical layer 2/3. J Neurosci 28:4377-4384. CrossRef Medline

Maffei A, Nataraj K, Nelson SB, Turrigiano GG (2006) Potentiation of cortical inhibition by visual deprivation. Nature 443:81-84. CrossRef Medline

Mainardi M, Landi S, Berardi N, Maffei L, Pizzorusso T (2009) Reduced responsiveness to long-term monocular deprivation of parvalbumin neurons assessed by c-Fos staining in rat visual cortex. PLoS One 4:e4342. CrossRef Medline

Mangini NJ, Pearlman AL (1980) Laminar distribution of receptive field properties in the primary visual cortex of the mouse. J Comp Neurol 193:203-222. CrossRef Medline

Markram H, Toledo-Rodriguez M, Wang Y, Gupta A, Silberberg G, Wu C (2004) Interneurons of the neocortical inhibitory system. Nat Rev Neurosci 5:793-807. CrossRef Medline

Medini P (2011) Layer- and cell-type-specific subthreshold and suprathreshold effects of long-term monocular deprivation in rat visual cortex. J Neurosci 31:17134-17148. CrossRef Medline

Mitzdorf U, Singer W (1980) Monocular activation of visual cortex in normal and monocularly deprived cats: an analysis of evoked potentials. J Physiol 304:203-220. Medline

Mrsic-Flogel TD, Hofer SB, Ohki K, Reid RC, Bonhoeffer T, Hübener M (2007) Homeostatic regulation of eye-specific responses in visual cortex during ocular dominance plasticity. Neuron 54:961-972. CrossRef Medline

Niell CM, Stryker MP (2008) Highly selective receptive fields in mouse visual cortex. J Neurosci 28:7520-7536. CrossRef Medline

Segal MB (1993) Extracellular and cerebrospinal fluids. J Inherit Metab Dis 16:617-638. Medline

Smith GB, Bear MF (2010) Bidirectional ocular dominance plasticity of inhibitory networks: recent advances and unresolved questions. Front Cell Neurosci 4:21. Medline

Tan AY, Zhang LI, Merzenich MM, Schreiner CE (2004) Tone-evoked excitatory and inhibitory synaptic conductances of primary auditory cortex neurons. J Neurophysiol 92:630-643. CrossRef Medline

Tsumoto T, Suda K (1978) Evidence for excitatory connections from the deprived eye to the visual cortex in monocularly deprived kittens. Brain Res 153:150-156. CrossRef Medline

van Versendaal D, Rajendran R, Saiepour MH, Klooster J, Smit-Rigter L, Sommeijer JP, De Zeeuw CI, Hofer SB, Heimel JA, Levelt CN (2012) Elimination of inhibitory synapses is a major component of adult ocular dominance plasticity. Neuron 74:374-383. CrossRef Medline

Yazaki-Sugiyama Y, Kang S, Câteau H, Fukai T, Hensch TK (2009) Bidirectional plasticity in fast-spiking GABA circuits by visual experience. Nature 462:218-221. CrossRef Medline

Yoon BJ, Smith GB, Heynen AJ, Neve RL, Bear MF (2009) Essential role for a long-term depression mechanism in ocular dominance plasticity. Proc Natl Acad Sci U S A 106:9860-9865. CrossRef Medline 